\title{
Career capital in global Kaleidoscope Careers: the role of HRM
}

\begin{abstract}
The results of this qualitative study of international talent show that although the acquisition of career capital through international assignments is perceived to be desirable both from an individual and organisational perspective, the global mobility needs and preferences of these two parties rarely coincide. This is due to the fact that individual mobility requirements come in cycles aligned to life cycle stages whereas organisational mobility needs ebb and flow like waves in response to perceived threats and opportunities. This presents opportunities and challenges for individuals in the acquisition and utilisation of career capital to balance work and non-work related demands in their global Kaleidoscope Careers. The role of HRM is to facilitate this process through mentoring, networking and other opportunities to engage in storying enabling employees to accommodate their changing needs at different life cycle stages. Failure to offer such support can manifest itself in demotivation, business performance issues as well as difficulties in terms of diversity and inclusion. Thus this paper offers a contribution to academic literature in the field of career theory as well as international Human Resource Management professional practice.
\end{abstract}

Keywords: global mobility, kaleidoscope careers, career capital, life cycle stages, international human resource management

\section{Introduction}

Globalization is a key, albeit contested, paradigm in defining developments in the international economic, social and political area (Prilleltensky 2012). It has been argued that this has resulted in an increase in global mobility which in turn is reflected in the workplace and attitudes to notions of career (Arnold \& Cohen 2008; Dickmann and Baruch 2011). Refining the all-encompassing definition offered by Koslowski (2011: preface) global mobility can be defined as; 'movements of people across international borders for any length of time for work-related purposes'. Until recently, research has tended to focus on 'traditional' expatriation i.e. an assignment of 3-5 years duration where the employee is sent by their organisation and accompanied by their 
family (Howe-Walsh and Schyns 2010). However there has been an increase in the number of employees declining such assignments due to mortgage concerns, family ties and dual career commitments (Froese, Jommersbach and Klautzsch 2013). In seeking to alleviate some of the factors identified, a variety different forms of global mobility have arisen, however for the purposes of this study, the focus is on (as defined by Dickmann and Baruch (2011): inpatriates (those temporarily transferred to corporate headquarters for development purposes), short term assignees (who complete projects that range from 3 months to 1 year in duration), 'globetrotters' (individuals who engage in frequent business travel) cross-border commuters (those who cross national borders to work in a different country on a daily, weekly, or in some rare cases as discovered in this project, monthly basis) and traditional expatriates. The increase in different forms of global mobility are indicative of a social change in attitudes to international careers (Sparrow 2006; Tams and Arthur 2007). In short, employees are less willing to accept organisationally-imposed global mobility choices, either in terms of the amount or form of international mobility (Shaffer, Kraimer, Chen and Bolino 2012). However global mobility remains a key requirement, particularly for those identified as 'talent' (Clegg and Baumeler, 2010).

This study is unique in that it encompasses all these forms of global mobility including individuals who follow the so-called 'new expatriation path' i.e. who are the driving force behind getting their employing organisation to relocate them, so-called corporate, self-initiated expatriates (Altman and Baruch 2012) as well as those who can be called 'traditional expatriates' (Dickmann and Harris 2005) i.e. those who embark on organisationally-driven international assignments. However, based on the analysis from the findings of a qualitative study within a large multinational, it is argued that mobility needs and expectations of employers and employees do not 
always coincide presenting challenges for the management of globally mobile talent. Talent is defined here as: 'those individuals who can make the greatest difference to organisational performance, either through their immediate contribution or in the longer term by demonstrating the highest levels of potential'(Tansley and Sempik 2008; Tansley and Tietze 2013 pp.1800)

This study adopts an interpretivist approach which focuses on how people make sense of their careers, offering, as Redman and Wilkinson (2001 pp.272) state, an; 'illuminating, and often missing, perspective on the ways in which individuals construct and experience their careers'. It is well-documented that international assignments may be sought and offered in pursuit of the accrual of career capital (Inkson and Arthur 2001; Dickmann and Harris 2005; Dickmann and Doherty 2008 and others). It is argued here that negotiations over the amount, form and frequency of global mobility are in themselves opportunities to acquire and utilise career capital in seeking a balance in globally mobile Kaleidoscope Careers. Thus the focus of this study is on two key questions; firstly, how do globally talent reconcile the competing work and non-work related demands which emerge at different stages in their life cycles and how might HR professionals facilitate these career decisions related to global mobility? For example, an organisational effectiveness consultant explained how his mobility needs and expectations had changed during his life cycle: 'I would just like to stress one point that we've talked about. Relate your mobility with your life cycle. I believe it's a key issue when you are in a phase of exploring being mobile, it's a perfect match but when you are building your family and your children are very young it's still easy to get mobile, but when they are 12,13, 14 years old it's getting harder and harder'. 
This paper offers a better understanding of the different organisational and individual global mobility demands through the metaphor of waves and cycles. Through this a greater insight into the lived experience of career capital and the Kaleidoscope Career is gained; thus making a theoretical contribution to career theory. Finally, in examining the role of HR in facilitating global mobility through mentoring, networking etc., this paper contributes to the practice of international human resource management.

Henceforth in the next sections, the literature relating to the kaleidoscope career and career capital are reviewed. The research methods are then presented, the findings reported and discussed and the key points from this study are highlighted in the conclusions.

\section{The Kaleidoscope Career Model}

The metaphor of the kaleidoscope is used to reflect how individuals change the pattern of their career by rotating the various aspects of their work and non-work lives to arrange their relationships and roles in new ways, much like the glass chips in a kaleidoscope form new patterns when the instrument is rotated (Mainiero and Sullivan 2005). Just as the kaleidoscope has three mirrors from which an infinite number of patterns are created; individuals focus on three career parameters when making career decisions, which are; authenticity (linked to notions of identity and being true to oneself), balance (of work and non-work interests) and challenge (need for stimulating work and career advancement). The authors posit that individuals will evaluate their choices and options to seek the best fit between work demands, constraints and opportunities as well as relationships, personal values and interests based on these parameters. 
Different studies drawing on this conceptual lens have focused on a number of parameters; the original research explored the so-called 'opt out revolution' a term used to explain why many talented women do not aspire to the higher echelons of management and concluded that guidelines are needed to help women increase their career success (Mainiero and Sullivan 2005). Generational differences in attitudes to work were explored by Sullivan, Forret, Carraher and Mainiero (2009) who asserted that HR initiatives need to be tailored to meet the differing generational needs for authenticity. Sullivan and Baruch (2009) reported that there has been an increase in importance attributed to authenticity, balance and challenge in relation to both gender and life span. Research supporting the parameters identified in this model (see Godshalk, Noble and Line 2007, Cabrera 2007, Grady and McCarthy 2008 and SmithRuig 2009) suggest that over the course of an individual's life span, they are constantly adjusting their career pattern to accommodate their various needs and constraints, with the strength of different parameters changing in response to different stages in their lives. Thus at the heart of the Kaleidoscope Career Model lies the need to make sense of and enact career choices whilst reconciling identity conflicts that this might invoke. For individuals engaged in a globally mobile career, the need to achieve authenticity, balance and challenge in their work and non-work lives is an on-going feature (Dickmann and Baruch 2011). The next section explores how career capital acquisition can be both a motivator for global mobility and a facilitator in achieving 'best fit' in Kaleidoscope Careers.

\section{Career Capital and Global Mobility}

The desire to acquire so-called 'career capital' can be a driving force acting as either a motivator to accept or decline a global mobility opportunity (Stahl \& Cerdin 2004; 
Tams and Arthur 2007). Career capital is defined by DeFillippi and Arthur (1994) as knowing-how, knowing-whom and knowing-why competencies which relate respectively to possessing career-related competencies and skills, having intra-and inter-firm networks and having a fit between an individual's identity and their careerrelated choices.

Adopting a broader view, Dickmann and Doherty (2008) conclude that there is a dual-dependency between employer and employee and some shared expectations in terms of career capital needs and outcomes in expatriate career management situations, however, there are 'significant differences' in terms of employee and employer assessments of the factors that influence individuals to accept international assignments. They conclude that such a mismatch of perceptions raises questions about standardised approaches to mobility policy and practice which may overlook the different needs of the diverse groups of employees. However as key findings from this study show, differences in perceptions of the factors that influence employees to accept or decline expatriate assignments is only one issue; the actual mobility needs of the two parties themselves may not always match. This can be attributed in no small measure to the differing life cycle demands which individuals need to balance throughout their Kaleidoscope Careers (Mainero and Sullivan 2005). However, the acquisition of career capital, it is argued in this paper, can be instrumental in helping individuals achieve a balance in their Kaleidscopic Careers and in facilitating this, employers can help to bridge the gap between different mobility needs. For example, a senior manager in this study explained how he negotiated an alternative to an expatriate assignment to the US due to the need to balance his work and non-work commitments, namely his family who lived in Switzerland. He described how he was able, using his knowing-how skills, to negotiate to be allowed to commute across time 
zones for the duration of the project. As he explained: 'Well I was not going to expat anyway, so it was what the company wanted that meant we found a deal.' Thus the employer also entered into negotiations resulting in a mutually satisfactory outcome and offering the employee the opportunity to balance his career needs. As the numbers of dual career couples continue to rise (Känsälä, Mäkelä and Suutari 2014), the challenge for individuals to find a balance work and non-work demands has become greater as there is often a requirement to coordinate not one but two individuals' career needs.

Such dual-career couples are defined as couples who are both 'psychologically committed to their professions'(Mäkelä, Känsälä and Suutari (2011 pp.185).This creates an added tension for those engaged in globally mobile careers as a spouse's willingness to relocate has a significant impact on whether or not an expatriate assignment is accepted (Collings, Doherty, Luethy and Osborn, 2011). It is perhaps unsurprising that there has been a rise in the numbers of dual-career couples unwilling to accept international assignments (Harvey, Napier and Moeller, 2009) as the complexity of balancing not one but two Kaleidoscope Careers may be too great. It may be surmised that this reluctance might extend to other forms of global mobility; however, as Demel and Mayrhofer (2010) note, due to the scant research into other types of mobility little is known about the additional challenges this presents for global organisations. They observe however, in their study of frequent flyers within Europe, that work and non-work role conflicts are particularly high in dual career couples.

\section{Methododolgy}

This study was approached from a social constructionist view that the world is to some extent socially constructed (through language, symbols etc.) but that there is a reality 
that exists outside of discourse, albeit that it is perceived differently by individuals depending on their backgrounds, culture etc. as per Liebrucks (2001). Thus this research was designed to explore not only the perceptions of what influences global mobility choices of 'talented' managers within the organisation, but to locate this analysis in the wider international context by examining both the external and organisational factors that also influence such global career decisions.

\section{Qualitative Interviews}

The case organisation is a major multinational with a world-wide international presence where global mobility is seen to be an essential part of management and career development, but also an operational necessity to manage teams based around the globe.

Thus the study was designed to examine, how the acquisition of career capital impacts on an individual's ability to balance work and non-work related demands in a kaleidoscope career and; how might HR professionals facilitate the achievement of 'best fit' in globally mobile Kaleidoscope Careers. Uniquely, this study included a number of globally mobile HR managers within the sample.

A combination of in-depth, semi-structured face-to-face and telephone interviews was carried out by the author between April 2008 and February 2009. Some of the interviews were undertaken face-to-face in the head offices of the case organisation in America. In the main, these participants were considered to be 'top-level talent' and formed part of the corporate management team. The remaining interviews had to be undertaken by telephone due to the challenges presented by both the global mobility of the participants and the geographic locations in which they were based. The duration of the interviews varied as might be expected in open, exploratory studies of this nature. The length depended on how many different forms of mobility 
the individual participant had experienced and ranged from one to $2 \frac{1}{2} 2$ hours. A copy of the interview guide can be found at Appendix I. The interviews were digitally recorded and transcribed, with the sample selected being representative of the target population in terms of age, gender, ethnicity, length of service etc. Table 1.0 below shows the sample profile:

[Insert Table 1.0 about here]

Theoretical sampling (Huberman and Miles 2002) was used to purposively select particular individuals (identified by the case organisation sponsor to be in talent pools and also to be globally mobile in different forms) who served to illustrate differing examples of the concepts in the study, i.e. those faced with global mobility choices operating in different cultures and contexts across the case organisation. In order to ensure that the views of participants engaged in all forms of global mobility were included in the study, so-called heterogeneous or maximum variation sampling was used i.e. individuals were approached on the basis that collectively their differing experiences were likely to represent the full range of different mobility choices that might be faced. Whilst theoretical sampling is undoubtedly an on-going process; the question nevertheless arises as to when to stop. This research study was approached from the perspective described by Charmaz, namely; to 'grapple' with the data until no further new theoretical insights emerged.

\section{Analysis}

This qualitative study was exploratory in nature and adopted elements of the grounded theory approach as described by Strauss (1987) and Strauss and Corbin (1998) in so far as the literature was accessed as a guide to the study; although the process was both inductive and iterative as the 
researcher moved from the data to the theory in coding and analysis. This pragmatic approach (as per Mounce 2002) was adopted to identify preliminary codes and themes and then to refocus these as comparisons across transcripts highlighted similarities and differences in participants' global mobility experiences. Frequency of recurring themes and observations from transcripts were recorded in order to give an indication of the strength of shared feeling, however the focus was also on the discourses and narratives told by participants which offered thick description (Geertz 1973) reflecting details of the culture(s) in which these individuals work.

Once initial coding had produced a relatively large number of codes, these were scrutinised to see which were the most significant and/or frequently used to determine which made the most analytic sense. This was done by comparing findings across transcripts, and identifying where there were similarities and differences between different participants' global mobility experiences. Thus more focused final coding categories were produced namely; 'balance and life cycle stage', 'power and mobility', 'consent versus coercion', 'networking and time' and 'on-going identity work' were used to inform the development of career theory. Table 2.0 below shows the development of the coding categories:

[insert Table 2.0 about here]

It was at this stage that 'memos' started to be produced to capture thoughts and connections. Charmaz (2006:72) advocates writing successive memos which involves "conversing with yourself" to discover your ideas about the data.

In a pivotal memo connections started to be made between the coding of influences on mobility and the form and extent of mobility which individuals will 
agree to in order to achieve a balance in their Kaleidoscope Career. In writing this links were made between career capital notions of knowing how skills (including power and consent), knowing who (networking over time) and knowing why (on-going identity work). The metaphor of waves and cycles of mobility connected to life stages was developed illustrating the lack of synchronicity between corporate and individual mobility needs. Thus codes were developed iteratively with the researcher moving between the data in the transcripts and the concepts in the literature to, at times, inductively and on other occasions, deductively identify and develop appropriate codes.

\section{Findings:}

\section{Life Cycle Needs \& Balance}

A key finding from this study is that the way in which external and internal forces influence global mobility choices vary depending on the life cycle needs of the individual at any point in time. The majority of participants stated that the ability and willingness to be mobile comes in phases (if it comes at all) linked to life stages. As illustrated in the Kaleidoscope Model (Sullivan and Baruch 2009) a key factor for many participants was linked to their need for balance between their work and nonwork lives. Thus a flexible approach to managing global mobility is essential. Participants felt very strongly about this as this comment demonstrates: 'Because I think it's about life stage, it's about what's going on with your kids; it's about what's going on with your spouse'. Another participant also explained how he had to revaluate his career and life choices as per the Kaleidoscope Career Model (Sullivan and Baruch 2009) and place more emphasis on balancing his work and non-work life to provide stability for his children; 'Yeah, I think the mobility goes with phases, life 
cycle. So it's when people are young and up to 12 years old and they want to have stability for the children up to 18 and then after that when the children are out of the house and they are more...they are ready again to move on'. This participant opted travel from the US to Europe (where he is currently on an expatriate assignment) on a bi-weekly basis until his children are finished school in the US.

For other participants, the health care needs of elderly relatives forced them to reconfigure their careers, adjusting the glass pieces in the kaleidoscope to accommodate the care of these dependents. For example, a senior manager in the global diversity and inclusion unit based in the US explained how she had to refuse an opportunity to expatriate to Singapore, an opportunity which she said she would have 'loved'. She described how she uses technology, such as conference calls and skype, combined with business travel as an alternative to embarking on an international assignment.

So, although 21 out of 38 participants stated that one incentive to pursue a globally mobile career for them was to have new experiences in unfamiliar countries and cultures, as one participant put it; 'I just love getting involved in different countries and cultures!', nevertheless willingness to be globally mobile is strongly governed by the needs and aspirations of their partners and other family members. This is particularly the case for dual-career couples.

\section{Dual Career Couples}

In this study, participants reported instances of negotiating alternatives to expatriation (such as commuting, shorter assignments or business travel) or leaving their partner (and children) in their country of origin when they relocate in order not to disrupt their spouse's career. Others described a phenomenon of 'taking turns' with both partners 
alternately having the 'leading' career and the partner becoming the trailing spouse; another turn of the Kaleidoscope in order to achieve the 'best fit' between their needs for authenticity, balance and challenge (Sullivan and Baruch 2009).

So to accommodate the need for challenge (stimulating work and career advancement) that dual careers present requires another shift in the Kaleidoscope for both the employee and their partner. A senior female participant in this study explained why she decided to take a less globally mobile post to achieve both a better work-life balance for her newly adopted children, but also to accommodate the demands of her husband's career. As she put it; '(It's) very much about my husband's career because I'm part of a dual career couple and always have been.'

To attempt to match the life cycle needs of, in effect, both partners is a challenge. Harvey et al. (2009) develop a 'family-life-cycle-stage' model to identify 'strategic windows of opportunity' to relocate employees; although this is not empirically supported. However, commentators do agree that there is a need for HR professionals to provide appropriate support to dual career families. From an expatriation perspective this includes: pre-departure cross-cultural training for both partners (and family), appropriate compensation (to accommodate the loss of earnings), consideration of the location in order to maximise the chances of the spouse obtaining employment, flexible housing arrangements, job seeking support or even the creation of job opportunities for the spouse (Harvey et al. 2009; Collings et al. 2011). Further research is needed to identify what support those engaged in other forms of global mobility require.

Thus the main influences on global mobility choices cited by participants in this study were; career of spouse or partner; future career prospects; nature of the role and, in the case of expatriation, willingness of spouse/family to be mobile. These 
influences can work to promote or deter mobility and, may not always remain the same. On occasion, a force that may at one time have operated as a deterrent may later become a driver to accept. For example, one participant described how his partner had been resistant to accepting expatriate opportunities, but then changed her mind once her children left home. Thus he came to accept an expatriate assignment despite not wishing to do so; 'Yeah, I didn't want to go, my wife did!' Another stated he felt that he had to agree to be mobile due to the potentially negative effect a refusal might have on his career. As he put it; 'If you say no I'm not doing this then you know, your file's marked, isn't it?'

As stated previously, the situation within this case organisation is complex as there are numerous forms of mobility engaged in and, to some extent, some individuals have a choice over which they select. For instance, one very senior participant described how he was able, by dint of his seniority and amount of previous mobility experience, to refuse to expatriate to the US for three years. Instead, he negotiated to commute from Geneva to Minneapolis on a monthly basis for the duration of the project he was engaged on. This illustrates that there are forces operating not only in terms of whether or not an individual will agree to be mobile (at all) but also with respect to which form of mobility (s) he will attempt to negotiate at any given point in their career.

A key influence on such mobility decisions was found to be the stories individuals told about their experiences. For example, as one participant explained; 'And people can go out and find, you know, learn about different stories.' As individuals seek to make sense of their experiences, they focus on and extract clues from situations that occur and the experiences of others around them. In the search for plausibility Glanz (2003) concludes that individuals exchange stories and associated 
narratives to bestow meaning and make sense of novel situations. In this search for meaning, individuals will access stories from a number of individuals, not necessarily (just) their line managers.

In this study, the main sources of stories for the majority of participants were, in order of priority; those told by peers and colleagues, those from (trusted) superiors, friends and family. These stories are exchanged as part of what Defillippi and Arthur (1994) call the acquisition of career capital. In other words, how individuals accrue knowing-how career competencies, knowing-whom (networks) and knowing-why (the fit between a person's identity and their career choices).

\section{Knowing-How: Not all about Skills}

There was a strong rhetoric within the case organisation with respect to the importance of career self-management, with one third of participants stating that individuals should be entirely responsible for managing their own careers. However, as discussed, this can prove difficult for those individuals who see themselves as less valued and/or less powerful than others. For example, a participant described how, when faced with the choice to relocate he has opted to leave the organisation as he felt he was not in a position to negotiate an acceptable alternative. On the other hand, a number of individuals described how they have been able to use their seniority and power as 'leverage' and their negotiating skills (knowing how competencies) to either 'bargain' for an alternative form of mobility or to decline to be mobile at all on occasion.

Thus they may negotiate a more acceptable 'deal' for themselves with respect to any global mobility opportunities that arise; rearranging the glass chips in the kaleidoscope (Mainiero and Sullivan 2005) to better suit themselves. However, as Drory and Vigoda (2010), note politics can have a positive or negative influence on 
HR activities such as selection, performance evaluation and promotions. Furthermore, some political environments within organisations can become dysfunctional. Such arenas are typified by less positive social capital behaviours such as managers not offering appropriate psychological and practical career support including failing to recommend them or barring their access to information regarding career progression opportunities (Grimland, Vigoda-Gadot and Baruch 2012).

This type of behaviour was described by a number of participants in the study who stated that their career moves have sometimes been hampered by negative political manoeuvring (Drory and Vigoda-Gadot 2010) and the actions of 'gatekeepers' (King 2004) i.e. managers who seek to block such moves. On the other hand, managers use 'the tap on the shoulder' as it is known in the case organisation to circumvent formal recruitment processes and 'poach' talent from other business units.

This element of career capital is reinforced by the degree to which individuals are able to forge and maintain a network to support their career self-management; thus knowing-how career capital can also operate as an influence on global mobility choices and on achieving a balance in a Kaleidoscope Career. Therefore in terms of HR's role, there is clearly a need to provide development opportunities for less experienced individuals to acquire these competencies in order that they are able to more effectively manage their careers.

\section{Knowing-Whom: A Question of Time}

Findings from this research show that knowing-whom is central to establishing networks to support individuals who are making global mobility choices. As one organisational consultant said: 'So you just need - you need the ability to- you need to understand there's no formal processes to do ' $\mathrm{x}$ '. No-one's going to tell you exactly 
how to go about it; but you need to work out - ok - so who do I need to influence, who do I need to have a coffee with'. However, the strong reliance on informal networks for guidance in relation to career decisions presents problems for some individuals as the establishment and successful operation of such networks is dependent upon a number of factors including: the network of the employee's manager, the ability (knowing-how competencies) of the individual concerned and the proximity of the individual to a corporate hub (or contacts they have made within such hubs). For example, a senior manager explained how the geographical location of an individual might inhibit their ability to take an advantage of an opportunity for career progression: 'But if I'm working as an engineer in Memphis Tennessee I may not have as strong a reach and I may have to do a little bit more work to express my interest.'

The majority of these factors are related to the length of tenure the person has had with the organisation and in turn, the amount of time and training they have had to develop the requisite knowing-how skills and/or the position and number of contacts they have made. The importance of having multiple mentors and a diverse support network has increased as career paths have become less predictable (De Janasz, Sullivan and Whiting 2003). Clearly some of these links are forged through experiences of global mobility; however for those new to the organisation or who have yet to gain sufficient mobility experience, there is a need to complement these informal network practices with more formal approaches such as mentoring as argued by Bozionelos (2003).

Aside from the management of practicalities to do with actual relocations and associated reward packages which is handled by the Global Mobility Unit, within the case organisation, organisational support provided is on an informal, voluntary basis. For instance, senior managers and their families with global mobility experience, 
mainly of expatriation, provide guidance to colleagues if they become aware that they are considering such moves or have recently relocated. Reliance on such informal processes can lead to problems of exclusion as well as issues with the quality and accuracy of information provided. This can influence an individual's identity work as such interactions (or lack of them) will shape how they interpret and enact their career choices. A further means of influencing an individual's identity formation and sensemaking is by conferring on them an identity, such as, in this case study, the label of 'talent' as discussed in the next section.

\section{Knowing-Why: Cycles in Cycles}

Participants in this study were those who had been identified as 'talented' and therefore were expected to be globally mobile. Identity can be defined as: 'the individual's own notion of who and what they are' (Watson, 2008: 131). As Kohonen (2005 pp.24) asserts; we obtain the 'ingredients for our identity development' from the ways in which we are treated by others. Therefore, it was of interest to explore the extent to which being labelled as 'talent' in itself influenced globally mobile Kaleidoscope Career.

It was clear from the findings that for some the use of discourses about talent and mobility and other 'cultural media' did indeed implicitly regulate identity to some degree (Alvesson and Willmott 2002; Alvesson, Ashcroft and Thomas 2008). Therefore 'talent' as an identity did have an influence on how competing work and non-work related demands were reconciled, particularly with regard to how global mobility choices were viewed and evaluated. On the one hand, a senior manager explained how being labelled as 'talent' afforded an individual power when making global mobility choices: 'And I think from the whole global talent perspective the 
leverage has shifted from the employer to the employee.' This was illustrated by a story related by a member of the Corporate Management Team who, due to her perceived level of talent, was able to re-set the glass in her Kaleidoscope Career by securing a less mobile job in the US headquarters when she adopted two children.

On the other hand, for some individuals, being labelled as 'talent' was an 'antiidentity' or negative identity (Sveningsson and Alvesson 2003) due to its underlying message 'talent must be mobile'. As one participant who had opted to commute rather than to expatriate explained; 'I mentioned that by taking this decision to be commuting I refused to be considered as a talent guy'. As the participants told their career 'stories', they referred to themselves in various ways depending on whether they wished to place more emphasis on their 'work identity' or their identity/ies in the wider community. Thus as they storied they described themselves alternately as a manager or an expatriate or a husband or a father/wife or mother etc. reflecting their attempts to negotiate a 'fit' between different work and non-work identities. However, this is not to suggest that one identity always predominated, on the contrary one participant described himself as simultaneously being 'a chemical engineer', 'a sales guy', 'a commuter' and 'a European'.

What was evident was that participants felt the influence of multiple identities (Kirpal 2004). This so-called 'boundary perspective' (Kriener, Hollensbe and Sheep 2006) helps illustrate how identity formation is subject to many influences. Indeed, as Kohonen (2005) asserts, international assignments themselves offer 'special instances' for re-shaping identities and engaging in sensemaking. Furthermore, in the complex and fragmented environment in which the case organisation operates, opportunities for identity construction can be as Musson and Duberley (2006) posit; 'an on-going cycle'. 
However, as stated previously, the results of this study show that individuals can, to some extent, enact their own environment and slow-down or indeed speed-up the opportunities for global mobility and identity (re)formation by the choices they make. Thus, identity work, just as other influences identified, operates in a cyclical fashion accelerating or slowing down in tandem with global mobility choices made at different life cycle stages. These findings are depicted in Figure 1 below.

Insert Figure 1 about here

This clearly presents a cycle of dilemmas and challenges for the individual as they seek to (re)construct their identities and engage sensemaking in the light of their perceived choices. As argued previously, listening to and telling stories is part of the process by which individuals make sense of these choices. Thus the role of HR is to facilitate the exchange of stories through assisting in the forging of networks as well as through other mechanisms, such as, through the use of the intranet to encourage individuals to post stories and exchange experiences of global mobility with colleagues; as per the conclusions drawn by Glanz (2003) in her study on expatriate mobility.

\section{Discussion}

Key findings show, notwithstanding the dual-dependency that exists between employer and employee (Dickmann and Doherty 2008), the situation is complicated by the need to achieve a balance between individual work and non-work demands and organisational mobility needs. This is made more challenging by the fact that influences on mobility choices come in cycles from an individual perspective aligned to differing life stages thus prompting a change in the configuration of the glass chips 
in the Kaleidoscope Career (Mainiero and Sullivan 2005). Whereas from an organisational point of view, mobility requirements ebb and flow in waves depending on the perceived opportunities and threats in the environment in which the firm operates. Thus, it is clear that the two parties' mobility needs and preferences may not always coincide, making it difficult to achieve a balance to accommodate individual life cycle needs.

The first aim of the study was to explore how the acquisition of career capital can enable globally mobile talent to reconcile the competing work and non-work related demands which emerge at different life cycle stages. Findings from this study show that individuals engaged in sensemaking through the exchange of stories and networking to acquire career capital. The knowing-whom and knowing-how career capital gained through networking enabled them to enter into negotiations with line managers over the form and timing of global mobility they would engage in. The success of such bargaining was linked to their perceived level of seniority, and in turn, the amount of career agency this offered them. However, the amount and form of global mobility could detrimentally affect their ability to network, as could their geographic location with those furthest away from the corporate hub in the US reporting the most difficulties.

In terms of knowing-why capital, there were few cases where individuals' embraced organisational attempts to create an aspirational identity (Thornborrow and Brown 2009) of 'talent', which was associated with being highly mobile. Where these efforts were unsuccessful, the notion of 'talent' became an anti-identity (Sveningsson and Alvesson 2003) for some leading them to decline to be part of the talent pool and, in turn, to refuse mobility opportunities. For the majority, identity work in this complex, highly fragmented environment was seen to be cyclical and on-going with 
individuals struggling to reconcile their conflicting work and personal identities and to satisfy competing global mobility needs.

The second aim of the study was to explore the role HR professionals might play in enabling 'best fit' between work and non-work demands in globally mobile Kaleidoscope Careers. It was found that the key to successful international HR policies is to ensure that they are flexible in order to meet the changing mobility requirements of employees over their life cycles. For example, for dual career couples the need to identify appropriate 'strategic windows of opportunity' (Harvey, Napier and Moeller 2009) to be globally mobile is vital. This flexible approach should encompass all aspects of global mobility and talent management ensuring integration both horizontally between policies and vertically with the overall business plan.

As employees attempt to reconfigure their Kaleidoscope Careers through balancing work and non-work related demands, it is argued that it is vital that HR practitioners design development schemes to ensure that individuals at all levels acquire the requisite knowing-how career competencies to engage in effective career self-management. In addition, diversity and inclusion at all levels needs to be encouraged, rather than allowing those with greater power bases to influence the internal recruitment and selection processes. Allied to this, to overcome the problems created by the over-reliance on informal, self-forged networks or knowing-whom career capital, a more formal mentoring programme and networking practices need to be introduced to facilitate the career self-management of less experienced employees and those with fewer sources of 'leverage'.

Finally, as this study shows, sensemaking is a highly social activity enacted through the exchange of stories. HR professionals can facilitate this through forging more robust, formal networks to complement the informal networks, and by utilising 
other media, such as technology, to encourage the exchange of stories. In this highly complex environment where demands for mobility are constantly changing, employers need to ensure that their HR policies and practices are flexible enough to accommodate both the waves and cycles of global mobility demands.

Thus the research contribution of this paper is threefold; firstly it contributes to the literature on global mobility by offering a metaphor of waves and cycles to explain why organisational and individual mobility needs rarely coincide. Secondly, it adds to the literature on career capital and Kaleidoscope Careers by illustrating how the acquisition and utilisation of career capital takes place, not only when actors are engaged in international mobility, but even in the process of negotiating and making decisions with respect to organisational mobility demands. Further, through developing an understanding of how opportunities to network and identity work impact on career capital acquisition it reveals the complexity of globally mobile Kaleidoscope Careers where balancing work and non-work demands at different life cycle stages presents ongoing challenges. Finally, it offers an understanding of how HR professionals can facilitate the achievement of 'best fit' in such global Kaleidoscope Careers, thereby adding to international Human Resource Management practice.

\section{Conclusions}

This research highlights how individual and organisational mobility needs may not coincide. This can be attributed to the fact that although subject to some of the same internal and external influences, individuals' mobility requirements come in cycles aligned to their life stages whereas organisational mobility preferences ebb and flow in waves in response to perceived threats and opportunities. This is the first study to adopt such a wide definition of global mobility as opposed to focusing solely on expatriate 
mobility and thus presents a more realistic picture of the globally mobile career engaged in by talent in contemporary organisations.

\section{Limitations of the study and directions for future research}

Utilising telephone interviews for some data gathering reduced opportunities to observe visual cues, such as body language, therefore it would be useful to extend this research by conducting more face-to-face interviews particularly with those individuals based in what might be seen to be 'hardship' locations. It would also be revealing to conduct a longitudinal study of those in globally mobile careers to ascertain how they make sense of their mobility choices at different stages in their lives. 


\section{References}

Altman, Y. and Baruch, Y. (2012) 'Global self-initiated corporate expatriate careers: a new era in international assignments?' Personnel Review, 41 (2) 233-255.

Alvesson, M. and Willmott, H. (2002) 'Identity regulation as organisational control producing the appropriate individual', Journal of Management Studies, 39, 619-644.

Alvesson, M., Ashcroft, K.L. and Thomas, R. (2008) 'Identity matters: Reflections on the construction of identity scholarship in organisation studies', Organisation, 15 (5), $5-28$.

Arnold, J. and Cohen, L. (2008) 'The psychology of careers in industrial and organisational settings: a critical but appreciative analysis', International Review of Industrial and Organisational Psychology, +23, 1-44.

Bozionelos, N. (2003) 'Intra-organisational network resources: Relation to career success and personality'. The International Journal of Organisational Analysis, 11(1), 41-66.

Cabrera, E.F. (2007) 'Opting out and opting in: Understanding the complexities of women's career transitions'. Career Development International, 12 (3), 218-237.

Charmaz, K. (2006) Constructing Grounded Theory. A practical guide through qualitative analysis, London: Sage Publications Limited 
Collings, D.G., Doherty, N. Luethy, M. and Osborn, D. (2011) 'Understanding and supporting the career implications of international assignments', Journal of Vocational Behaviour, doi:10.1016/j.jub.2015.03.010.

Clegg, S. and Baumeler, C. (2010) 'Essai: From iron cages to liquid modernity in organization analysis', Organization Studies, 21, (12), 1713-1733.

De-Fillippi, R. and Arthur, M. (1994) 'Boundaryless contexts and careers: A competency-based perspective', Journal of Organisational Behaviour, 15, 307-324.

De Janasz, S.C. and Sullivan, S.E. and Whiting, V. (2003) 'Mentor networks and career success: Lessons for turbulent times', Academy of Management Executive, 17 (4), 78-91.

Demel, B. and Mayrhofer, W. (2010) 'Frequent business travellers across Europe: Career aspirations and implications', Thunderbird International Business Review, 52 (4), 301-311.

Dickmann, M. and Baruch, Y. (2011) Global careers. Oxon: Routledge.

Dickmann, M. and Doherty, N. (2008) 'Exploring the career capital impact of international assignments within distinct organisational contexts', Journal of Management, 19, 145-161. 
Dickmann, M. and Harris, H. (2005) 'Developing career capital for corporate careers: The role of international assignments', Journal of World Business, 40 (4), 399-408.

Drory, A. and Vigoda-Gadot, E. (2010) 'Organizational politics and Human Resource Management: A typology and the Israeli experience', Human Resource Management, 20, 194-202.

Froese, F.J., Jommersbach, S. and Klautzsch, E. (2013) 'Cosmopolitan career choices: a cross-cultural study of job candidates' expatriation willingness', The International Journal of Human Resource Management, http://dx.doi.org/10.1080/0985192.2013.770782.

Geertz, C. (1973) The interpretation of cultures. New York: Basic Books.

Glanz, L. (2003) 'Expatriate stories: A vehicle of professional development abroad?' Journal of Managerial Psychology, 18 (3) 259-274

Grady, G. and McCarthy, A.M. (2008) 'Work-life integration: Experience of midcareer professional working mothers'. Journal of Management Psychology, 23, 599622.

Grimland, S., Vigoda-Gadot, E. and Baruch, Y. (2012) 'Career attitudes and success of managers: The impact of chance event, protean and traditional careers', The International Journal of Human Resource Management, 23 (6), 1074-1094. 
Harvey, M., Napier, N. and Moeller, M. (2009) 'Interpreting dual career couples' family life-cycles: Identifying strategic windows of global career opportunity', Research and Practice in Human Resource Management, 17 (2), 14-35.

Howe-Walsh, L. and Schyns, B. (2010) 'Self-initiated expatriation: implications for HRM'. The International Journal of Human Resource Management, 21 (2), 260-273.

Huberman, A.M. and Miles, M.B. (2002) The qualitative researcher's companion. London: Sage Publications Ltd.

Inkson, K. and Arthur, M. (2001) 'How to be a successful career capitalist', Organisational Dynamics, 30 (1), 48-60.

Känsäla, M. Mäkelä, L. and Suutari, V. (2014) 'Career coordination strategies among dual career expatriate couples', International Journal of Human Resource Management, http://dx.doi.org/10.1080/09585192.2014.985327.

King, Z. (2004) 'Career self-management: Its nature, causes and consequences', Journal of Vocational Behaviour, 65, 112-133.

Kirpal, S. (2004) 'Researching work identities in a European context', Career Development International, 9 (3), 199-221.

Kohonen, E. (2005) 'Developing global talent through international assignments', Personnel Review, 34 (1), 22-36. 
Liebrucks, A. (2001) 'The concept of social construction', Theory Psychology, Vol. 11, No. 3, pp. 363-391.

Mainiero, L.A. and Sullivan, S.E. (2005) 'Kaleidoscope Careers: An alternative explanation for the 'opt-out' revolution', The Academy of Management Executive, 19 (1), 106-123.

Mäkelä, L., Känsälä, M. and Suutari, V. (2011) ‘The roles of expatriates’ spouses among dual-career couples', Cross-Cultural Management: An International Journal,.18 (2), 185-197.

Mounce, H.O. (2002) The Two Pragmatisms. From Peirce to Rorty. New York: Routledge. ISBN: 97804151528399780203045213

Musson, G. and Duberley, J. (2007) 'Change, change or be exchanged: The discourse of participation and the manufacture of identity', Journal of Management Studies, 44 (1), 143-64.

Prilleltensky, I. (2012) 'The what, why, who and how of globalization: What is Psychology to do?' Journal of Social Issues, .3, 611-628.

Redman, T. and Wilkinson, A. (2001) Contemporary Human Resource Management. Texts and Cases. Essex: Pearson Education Limited. 
Shaffer, M.A., Kraimer, M.L., Chen, Y.P. and Bolino, M.C. (2012) 'Choices, challenges, and career consequences of global work experiences: A review and future agenda'. Journal of Management, http://jom.sagepub.com/content/38/4/1282.

Smith-Ruig, T. (2009) 'Making sense of careers through the lens of a path metaphor.' Career Development International, 13 (1), 20-32.

Sparrow, P. (2006) International recruitment, selection and Assessment. Research Report. Chartered Institute of Personnel and Development: London.

Stahl, K.G. and Cerdin, J.L (2004) 'Global careers in French and German multinational corporations', Journal of Management Development, 23 (9), 885-902.

Strauss, A. (1987) Qualitative Analysis. New York: Cambridge University Press.

Strauss, A. and Corbin, J. (1998) Basics of qualitative research: Grounded Theory procedures and techniques. $\left(2^{\text {nd }} \mathrm{Ed}\right)$ Thousand Oakes CA: Sage.

Sullivan, S.E. and Baruch, Y. (2009) 'Advances in career theory and research: A clinical review and agenda for future exploration', Journal of Management, 25 (6), $1542-1571$.

Sullivan, S.E., Forret, M.L., Carraher, S.M. and Mainiero, L.A. (2009) 'Using the Kaleidoscope Career Model to examine generational differences in work attitudes'. Career Development International, 14 (3), 284-302. 
Sveningsson, S. and Alvesson, M. (2003) 'Managing managerial identities: organisational fragmentation, discourse and identity struggles', Human Relations, 56, 1163-1193.

Tams, S. and Arthur, M.B. (2007) 'Studying careers across cultures. Distinguishing international, cross-cultural and globalizations perspectives', Career Development International, 12 (1), 86-98.

Tansley, C. and Tietze, S. (2013) 'Rites of passage through talent management progression stages: an identity work perspective'. The International Journal of Human Resource Management, http://dx.doi.org/10.1080/09585192.2013.777542.

Thornborrow, T. and Brown, A.D. (2009) 'Being regimented: Aspiration, discipline and identity work in the British parachute regiment', Organization Studies, 30 (4), $255-376$.

Watson, T.J. (2008) 'Managing identity: identity work, personal predicaments and structural circumstances', Organization, 15 (2), 121-143. 